\title{
Intensificação e alteração espetral da fluorescência de moléculas orgânicas por agregação ou complexação
}

\author{
Samuel Guieu $u^{1,2}$ \\ ${ }^{1}$ QOPNA \& ${ }^{2}$ CICECO - Aveiro Institute of Materials, Departamento de Química, Universidade de Aveiro, Aveiro, Portugal \\ sguieu@ua.pt
}

\begin{abstract}
Intensification and alteration of the fluorescence spectrum of organic molecules induced by aggregation or complexation - Organic fluorescent compounds have many potential applications, from luminescent materials to imaging of cells and tissues for biological studies. They are usually studied and used in very dilute solutions, to avoid interactions between themselves, which can lower the intensity of the emission. But some of them exhibit the opposite property, and are more luminescent when they interact with themselves or with other entities, due to the formation of aggregates or to the rigidification of their backbone. This peculiar behaviour is explained in this article and it is illustrated with fluorophores presenting the aggregation induced emission phenomenon or the formation of J aggregates, together with potential applications of these phenomena such as the production of luminescent materials and the detection of macrocycles.
\end{abstract}

$\mathrm{O}_{\text {s compostos orgânicos fluorescentes têm uma vasta gama de aplicações, desde materiais luminescentes até à }}$ marcação de células ou tecidos para estudos biológicos. Habitualmente, estes compostos são estudados e usados em soluções muito diluídas para evitar interações fluoróforo-fluoróforo que podem reduzir a intensidade da emissão. Mas alguns fluoróforos apresentam a propriedade oposta, e são mais luminescentes quando interagem com eles próprios ou com outras entidades, devido à formação de agregados ou à rigidificação das suas estruturas. Neste artigo, esta particularidade é explicada e ilustrada com famílias de fluoróforos que apresentam o fenómeno de emissão induzida por agregação ou por formação de agregados J. A produção de materiais luminescentes com esta propriedade e a sua utilização na deteção de macrociclos é também discutida.

\section{Introdução}

A emissão de luz é um fenómeno um pouco misterioso, mas fundamental para a humanidade, porque a visão é uma das nossas interações mais importantes com o meio ambiente. Por isso, têm sido desenvolvidas várias maneiras de produzir luz, desde a combustão até à eletroluminescência. A fotoluminescência é conhecida desde o século XVI, sendo observada primeiro em extratos de madeira e depois em materiais inorgânicos, mas demorou algum tempo até se conseguir uma explicação para esse fenómeno [1]. Com o desenvolvimento dos métodos de síntese orgânica, no século XIX foram produzidos vários corantes orgânicos para aplicação em pinturas ou como corantes alimentares ou de tecidos. Atualmente os compostos orgânicos luminescentes atraem muita atenção pois permitem aplicações diferentes das dos cromóforos inorgânicos. Além disso, e de uma maneira geral, são menos tóxicos porque não incluem metais, e isso é vantajoso para aplicações biológicas. Também são mais fáceis de modificar, o que permite afinar as suas propriedades para utilizações específicas, por exemplo em termos de cor de absorção ou de emissão. Mas os fluoróforos orgânicos também têm desvantagens e limitações, especialmente quanto à sua utilização em soluções muito concentradas ou no estado sólido. Habitualmente, quando as moléculas dos fluoróforos interagem entre si, formando dímeros ou agregados, por exemplo, elas perdem a capacidade de emitir luz. Por essa razão, os fluoróforos são normalmente estudados e usados em condições de alta diluição.
Recentemente foram descritas novas famílias de fluoróforos em que se verifica o fenómeno oposto: são fracamente emissores em soluções diluídas, mas a intensidade da emissão aumenta quando se encontram em soluções concentradas ou no estado sólido. Isto é, a fluorescência aumenta quando os fluoróforos interagem com eles próprios ou quando se encontram numa matriz rígida. Neste artigo, numa primeira parte, explica-se este fenómeno através dos processos físicos subjacentes à emissão de luz. Numa segunda parte, apresentam-se algumas famílias de fluoróforos com estas propriedades, bem como as potenciais aplicações que podem ser desenvolvidas aproveitando o aumento da intensidade de emissão em ambientes particulares.

\section{Emissão de luz}

A absorção e a emissão de fotões por compostos orgânicos estão ilustradas no diagrama de Perrin-Jablonski simplificado (Figura 1). O fluoróforo, por absorção de um fotão, passa do estado fundamental $\left(\mathrm{S}_{0}\right)$ ao estado excitado $\left(\mathrm{S}_{1}\right)$. Daqui, ele pode regressar ao estado fundamental por relaxação vibracional (processo designado por conversão interna) ou por emissão de fotões (fluorescência). O rendimento quântico, que mede a eficácia da emissão de fotões, é maior quando as vibrações são impedidas. O fluoróforo no estado excitado $\left(S_{1}\right)$ também pode sofrer um cruzamento intersistemas e passar para um estado excitado tripleto ( $T_{1}$, não indicado na Figura 1). Daqui, ele pode relaxar para o estado fundamental por relaxação não radiativa ou por emissão de fotões (fosforescência), embora este fenómeno seja raro nos compostos orgânicos. 


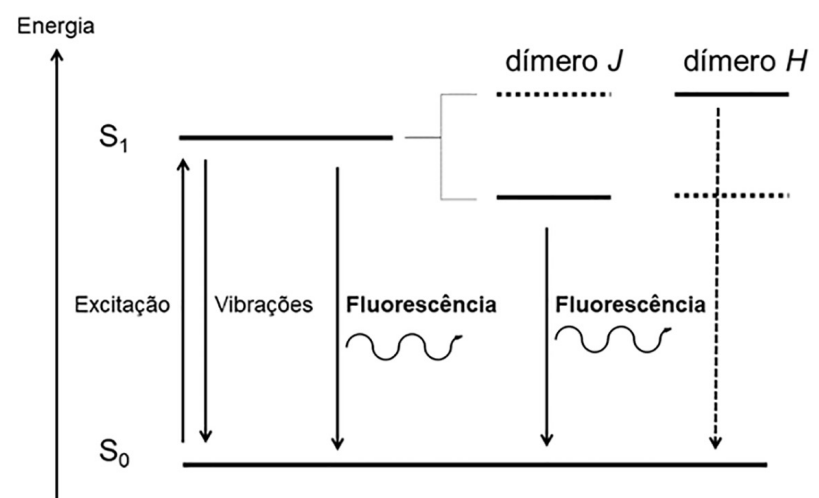

Figura 1 - Diagrama de Perrin-Jablonski simplificado ilustrando alguns dos passos de excitação e relaxação em fluoróforos orgânicos.

A emissão induzida por agregação é um fenómeno baseado na restrição das vibrações, em que um fluoróforo emite mais quando agrega do que quando se encontra isolado em solução [2-4]. Isso acontece com fluoróforos que possuem grupos que podem rodar livremente em solução e que promovem uma relaxação não radiativa dos fluoróforos depois da excitação. Quando estes fluoróforos se encontram na forma de agregados ou de cristais, estas rotações são restringidas, e aumenta a eficácia de emissão (rendimento quântico) (Figura 2a). Alguns fluoróforos só apresentam este fenómeno quando se encontram numa forma cristalina, e não na forma de sólidos amorfos [5,6].

A restrição das rotações nas moléculas também pode ser conseguida com os fluoróforos isolados. Isso é possível, por exemplo, tornando o meio rígido usando um solvente viscoso ou diluindo o fluoróforo num polímero solido. A fluorescência aumentada que se observa nessas condições pode ser usada, por exemplo, em sondas de viscosidade (auramina O, Figura 2b). a)

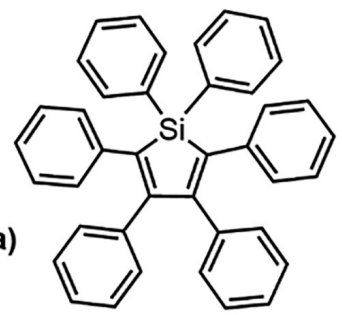

b)<smiles>CN(C)c1ccc(C(=[NH2+])c2ccc(N(C)C)cc2)cc1</smiles>

Figura 2 - Exemplo de fluoróforos com emissão induzida por agregação (a) e emissão modificada pela viscosidade (b).

Quando os fluoróforos orgânicos agregam em soluções saturadas, ou no estado sólido, podem-se formar entidades diméricas (Figura 1). Por exemplo, quando fluoróforos dipolares se encontram próximos uns dos outros, eles podem interagir também através de interações eletrostáticas formando dímeros ou oligómeros. Se consideramos o caso mais simples, um dímero, a nova espécie vai apresentar propriedades fotofísicas diferentes das do monómero. Dependendo do ângulo formado entre o eixo do dipolo e a linha entre os meios dos fluoróforos, o dímero é chamado dímero $J$ (ângulo inferior a 54,7º ou dímero $H$ (ângulo superior a $54,7^{\circ}$ ) [7]. Em ambos os casos, o primeiro estado excitado $\left(\mathrm{S}_{1}\right)$ está dividido em dois níveis (Figura 1 ). No caso do dímero $J$ o nível mais baixo tem uma transição per- mitida para o nível fundamental e observa-se um deslocamento batocrómico (para maior $\lambda$ ) com uma fluorescência aumentada [8-10]. No caso do dímero $H$, ocorre a situação contrária: há uma transição permitida do nível mais alto para o nível fundamental e, em consequência, é observada uma fluorescência muito fraca e com um deslocamento hipsocrómico (para menor $\lambda$ ). Este fenómeno foi observado inicialmente em pigmentos usados para observação de tecidos biológicos (Figura 3).

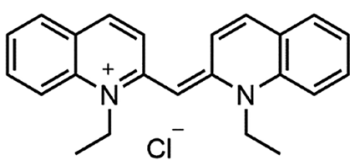

Figura 3 - Exemplo de um fluoróforo com propensão para formar dímeros $J$.

A modificação das propriedades fotofísicas dos fluoróforos tem várias aplicações, desde a produção de fluoróforos orgânicos que emitem no estado sólido para OLEDs até ao estudo de sistemas biológicos, incluindo a polaridade de membranas ou a viscosidade do meio intracelular.

\section{Exemplos e aplicações}

\section{Importância da estrutura cristalina}

Quando os fluoróforos se encontram em solução as rotações e vibrações não são restringidas. No entanto, no estado sólido, e dependendo do modo de cristalização, as rotações e vibrações podem ficar bloqueadas de maneira eficaz, ou não. Por exemplo, o composto apresentado na Figura 4 emite fracamente em soluções diluídas mas emite fortemente no estado cristalino [6]. Nos cristais desse composto, obtidos a partir de uma solução em diclorometano anidro, os grupos hidroxilo e carbonilo formam pontes de hidrogénio intra- e intermoleculares, o que rigidifica a estrutura de maneira eficaz e força as moléculas a organizarem-se de modo a que não haja interação entre os anéis aromáticos. Como consequência, a fluorescência aumenta. Ao contrário, nos sólidos amorfos, obtidos por precipitação a partir de uma solução de metanol e água, formam-se também pontes de hidrogénio com moléculas de água, o que perturba a organização do sólido e permite a interação entre os anéis aromáticos: neste caso, a luminescência é menor.

Este exemplo mostra a importância da organização dos fluoróforos no estado sólido para que o fenómeno de emissão induzida por agregação ou por cristalização se possa observar. E a organização dos fluoróforos nos cristais é ainda mais importante para a obtenção de agregados $J$.

\section{Sólidos orgânicos fluorescentes no vermelho}

Os complexos do tipo difluoroborodicetonatos (Figura 5) são polares e têm tendência a formar agregados em soluções concentradas [11]. Quando se compara a emissão desses compostos em soluções diluídas com a emissão no estado sólido, observa-se uma mudança de cor (Figura 5) e a eficácia da emissão melhora. Essa alteração é explicada pela formação de agregados $J$ no estado sólido. Os dímeros $J$ podem ser observados na estrutura cristalina destes compostos, por exemplo na do que está funcionalizado com 
a)

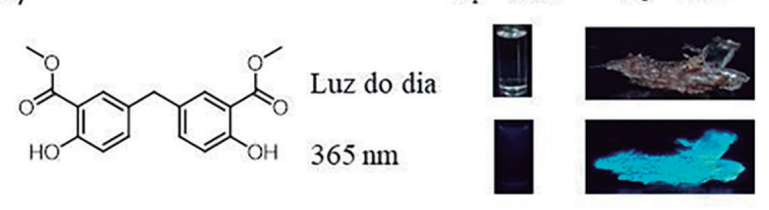

b)

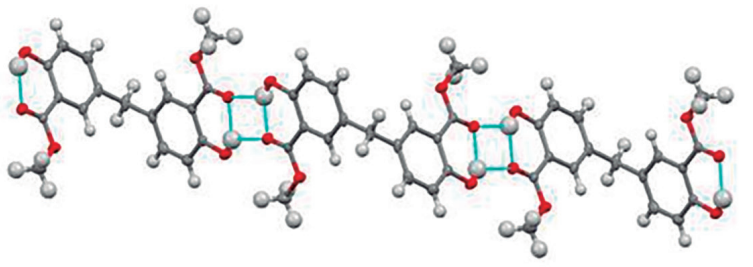

c)

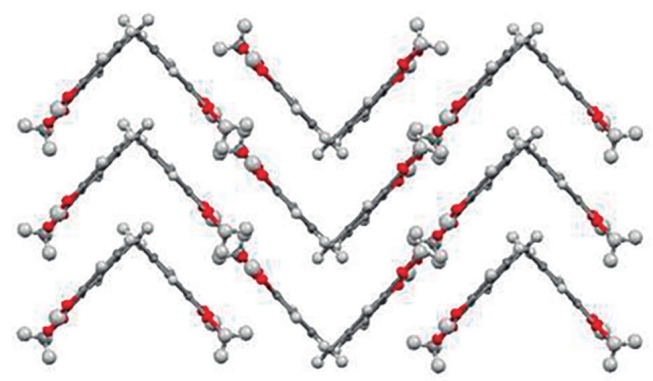

Figura 4 - Composto com propriedade de emissão induzida por cristalização. a) Estrutura, solução e cristais iluminados pela luz do dia e com uma lâmpada UV; b) Estrutura cristalina ilustrando as ligações ponte de hidrogénio; c) Estrutura cristalina ilustrando a ausência de contacto entre os anéis aromáticos. C, cinzento; $\mathrm{H}$, branco; $\mathrm{O}$, vermelho.

um grupo metoxilo (Figura 6). A formação de dímeros $J$ também pode ser observada em soluções concentradas (Figura 6). A formação de dímeros $J$ é uma maneira elegante de produzir sólidos orgânicos emissores de luz vermelha.
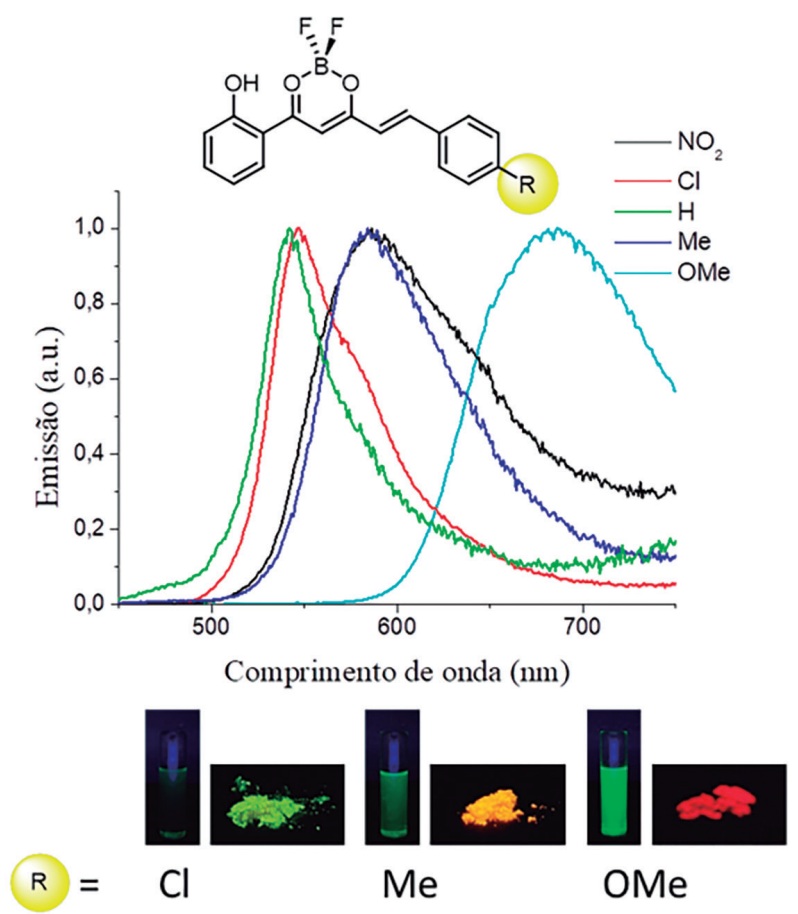

Figura 5 - Estrutura dos fluoróforos difluoroborodicetonatos e respetivos espetros de emissão no estado sólido. Soluções e cristais iluminados com uma lâmpada UV (365 nm).

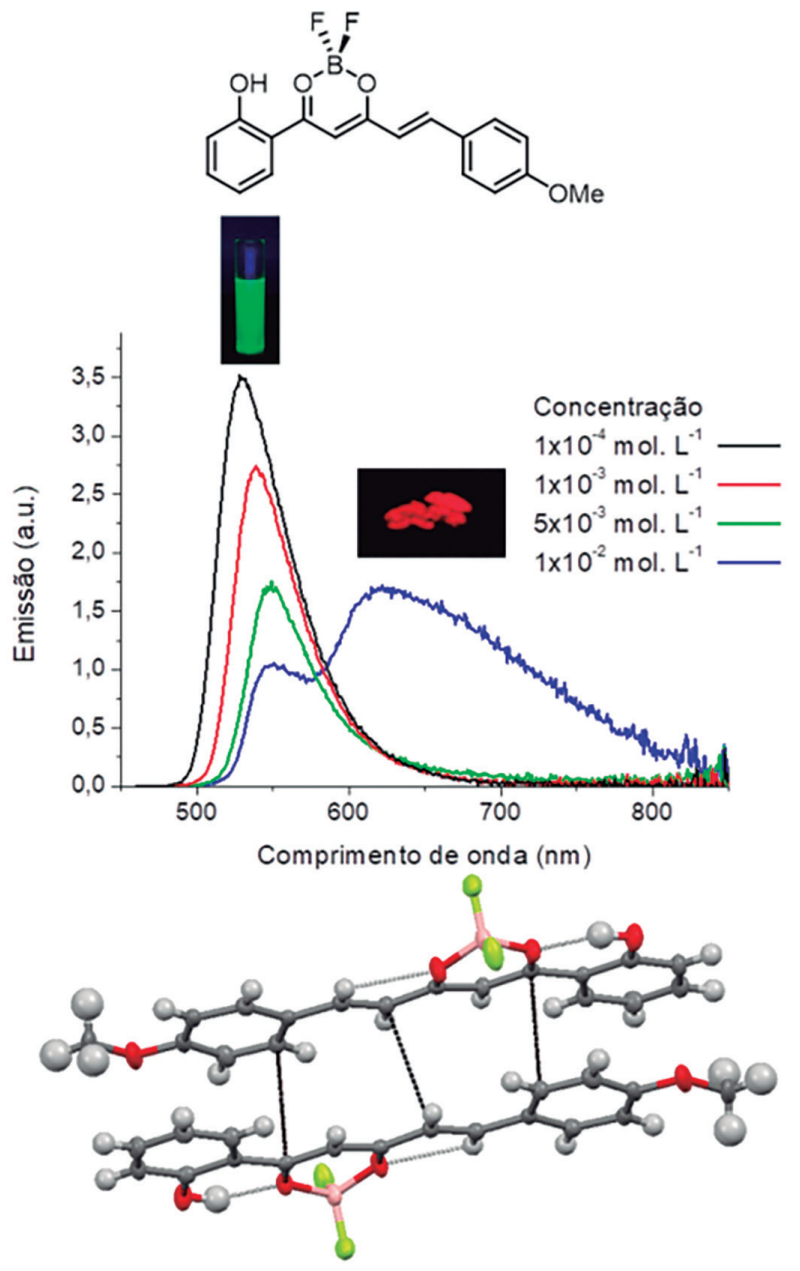

Figura 6 - Estrutura do fluoróforo difluoroborodicetonato $(\mathrm{R}=\mathrm{OMe}) \mathrm{e}$ espetros de emissão de soluções de diferentes concentrações. A banda à direita observada na solução $1 \times 10^{-2} \mathrm{~mol} \mathrm{~L}^{-1}$ é atribuída à formação de dímeros $J$. Estrutura cristalina do fluoróforo evidenciando a formação de dímeros J. C, cinzento; H, branco; O, vermelho; B, cor-de-rosa; F, amarelo.

\section{Emissão induzida por agregação ou complexação}

Os compostos com propriedades de emissão induzida por agregação podem ter aplicações biológicas diversas, nomeadamente na marcação de organelos em células ou tecidos biológicos, na deteção de analitos [12] ou na indução de apoptose celular em cancros [13].

Algumas dibenzaldazinas apresentam emissão induzida por agregação. O composto representado na Figura 7, por exemplo, revela essa propriedade quando se encontra dissolvido em misturas de THF e água. Em THF, o composto fica completamente dissolvido e não emite. Quando se aumenta a proporção de água, o composto começa a precipitar, a solução fica turva e o composto, na forma de pequenos agregados, emite uma luz amarela. Quando o composto se encontra na forma de cristais, a emissão é ainda maior. O gráfico de emissão ilustra este fenómeno de uma maneira quantitativa: a partir de $70 \%$ de água no solvente, a intensidade da emissão aumenta até ficar 250 vezes maior quando a quantidade de água atinge 95\%. Entretanto, o rendimento quântico do fluoróforo passa de inferior a $0,1 \%$ quando está totalmente dissolvido a cerca de $40 \%$ quando se encontra no estado sólido. 


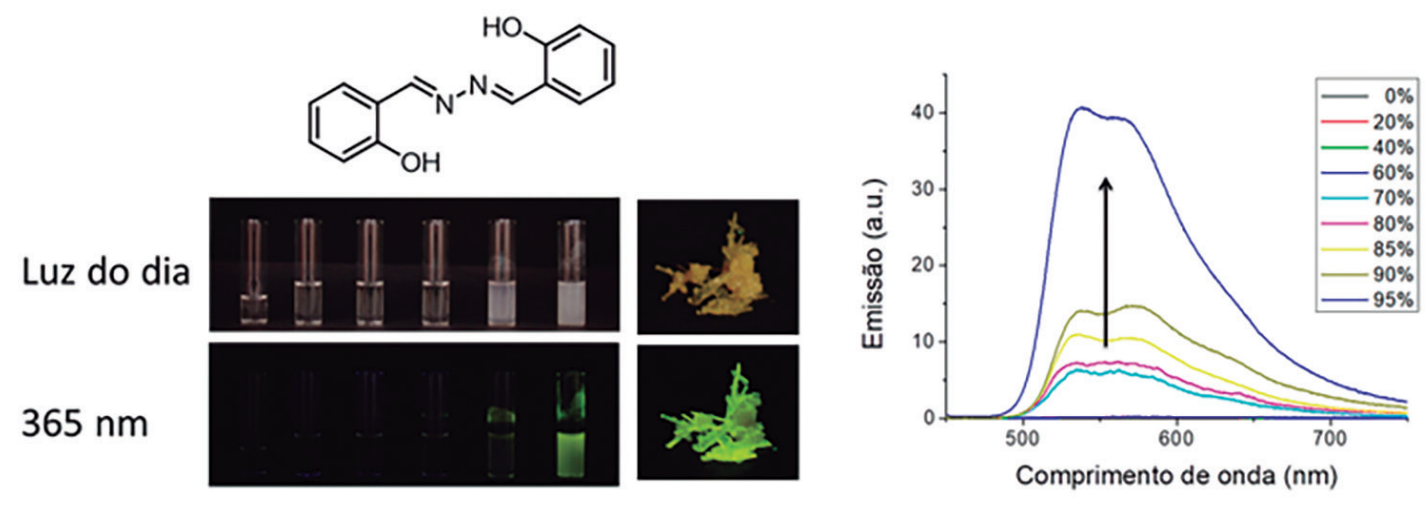

\%água emTHF 02040608090

Figura 7 - Estrutura do fluoróforo e a experiência ilustrando o fenómeno de emissão induzida por agregação.

O mecanismo de emissão induzida por agregação reside na restrição das vibrações no estado sólido [14]. Na estrutura cristalina do fluoróforo (Figura 8) [15] as ligações de hidrogénio intramoleculares rigidificam a molécula eficazmente e ela fica planar. No cristal as moléculas organizam-se em camadas que não contactam entre si, e em cada camada as moléculas apenas apresentam interações do tipo $\mathrm{C}-\mathrm{H} \cdots \mathrm{C}$, isto é, não há interações $\pi-\pi$ significativas entre os anéis aromáticos.
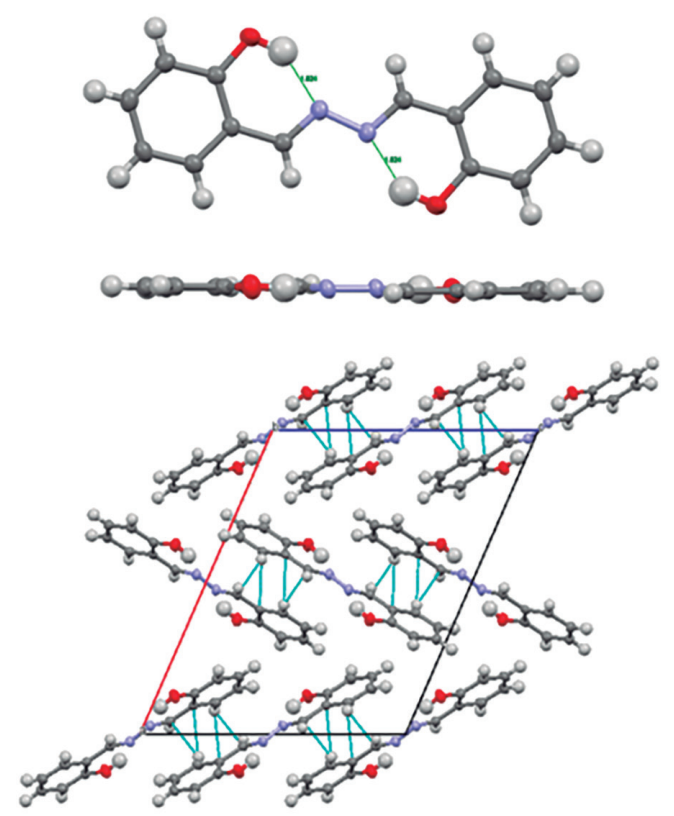

Figura 8 - Estrutura cristalina ilustrando as ligações de hidrogénio, a planaridade do composto e a ausência de contacto entre os anéis aromáticos. C, cinzento; H, branco; O, vermelho; N, azul.
O fluoróforo dibenzaldazina pode ser funcionalizado com grupos dadores ou sacadores de eletrões, o que influencia a cor de emissão (Figura 9). Os grupos dadores, como o metoxilo, deslocam a emissão para o azul, e os grupos sacadores (Br, por exemplo) deslocam a emissão para o vermelho.

A conjugação do sistema $\pi$ também influencia a cor de emissão (Figura 10): se for inserido um anel aromático entre os átomos de nitrogénio, ele pode ficar coplanar com os grupos hidroxifenilo, o que se verifica na estrutura cristalina, e a emissão desloca-se para o vermelho (efeito batocrómico).

Usando uma combinação das duas modificações (substituição com grupos dadores ou sacadores e aumento da conjugação do sistema $\pi$ ), é possível obter sólidos emissores em todo o espetro do visível (Figura 11), desde o azul até ao vermelho. Os rendimentos quânticos dos sólidos variam de $2 \%$ a $54 \%$, que são valores bastantes altos para compostos orgânicos no estado sólido.

Além da cristalização, foram desenvolvidos outros métodos para restringir as vibrações nos fluoróforos com o propósito de induzir ou aumentar a emissão. Uma maneira simples de alcançar esse objetivo consiste em funcionalizar os fluoróforos com grupos volumosos ou com anéis que liguem duas partes da molécula. Alternativamente, pode-se inserir o fluoróforo numa cavidade, por exemplo numa ciclodextrina. As ciclodextrinas (oligossacarídeos cíclicos) são capazes de formar complexos de inclusão, em água, com vários compostos hidrofóbicos (Figura 12). As dibenzaldazinas podem ser modificadas na sua periferia com grupos hidrofílicos (iões piridínio, por exemplo), permitindo a sua dissolução em água sem modificar as propriedades<smiles>COc1cc(O)c(C=NN=Cc2c(O)cc(OC)cc2OC)c(OC)c1</smiles>
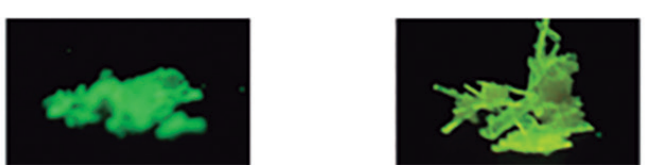<smiles>Oc1c(Br)cc(Br)cc1/C=N/N=C/c1cc(Br)cc(Br)c1O</smiles>

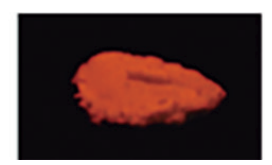

Figura 9 - Variação da cor de emissão em função do tipo de substituinte: dador de eletrões, neutro ou sacador de eletrões. 


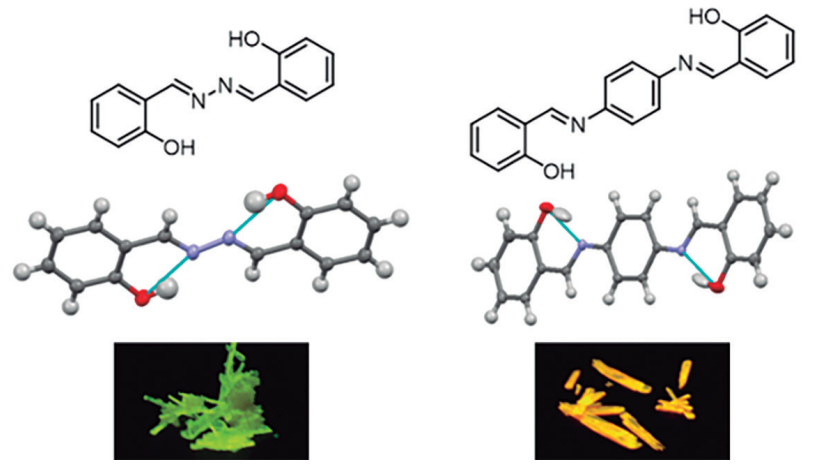

Figura 10 - Variação da cor de emissão em função da conjugação do sistema aromático. Estrutura dos fluoróforos, estrutura cristalina e fotografia dos sólidos iluminados com luz UV (365 nm). do grupo dibenzaldazino, nomeadamente a sua capacidade de emitir luz quando as suas vibrações ficam restringidas. Quando esses fluoróforos se encontram em solução aquosa diluída, a intensidade da emissão é reduzida. Quando se adiciona uma solução de beta-ciclodextrina a essa solução observa-se uma diminuição da intensidade da emissão: isso significa que o fluoróforo não interage com a ciclodextrina e observa-se apenas uma diluição da solução. Pelo contrário, quando se adiciona uma solução de gama-ciclodextrina observa-se um aumento da intensidade de emissão. Isso significa que o fluoróforo interage com essa ciclodextrina. A inserção do fluoroforo dentro da cavidade da gama-ciclodextrina foi confirmada por estudos de RMN que permitiram verificar que o complexo de inclusão é formado por um<smiles>CC(=Nc1ccccc1C)c1ccc(N(CC(C)C)c2ccccc2O)cc1</smiles>

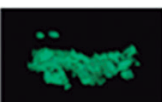

$6 \%$<smiles>COc1cccc(OC)c1CN=Nc1c(OC)cccc1OC</smiles>

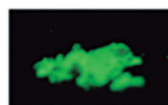

$11 \%$<smiles>COc1cc(O)c(C(=O)N=C(C)c2c(OC)ccc(OC)c2OC)c(OC)c1</smiles>

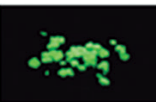

$19 \%$
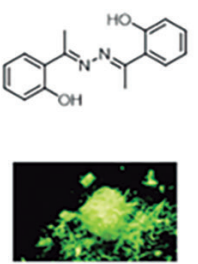

$54 \%$<smiles>Cc1cccc(C=NN=Cc2ccccc2O)c1O</smiles>

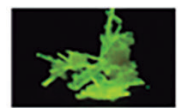

$40 \%$

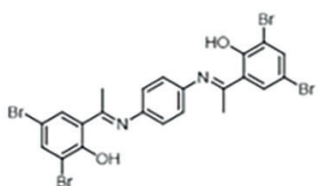

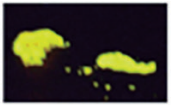

$7 \%$

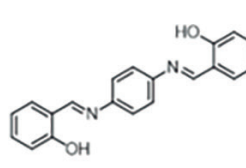

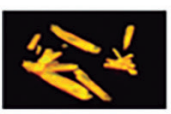

$44 \%$

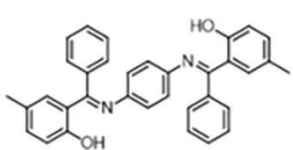

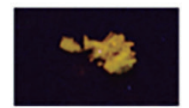

$2 \%$

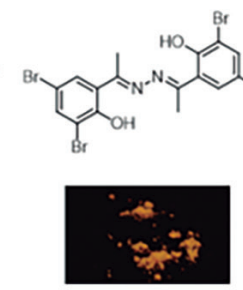

$13 \%$

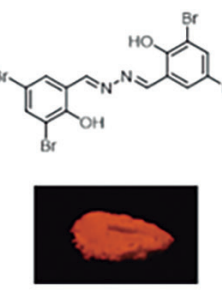

$10 \%$

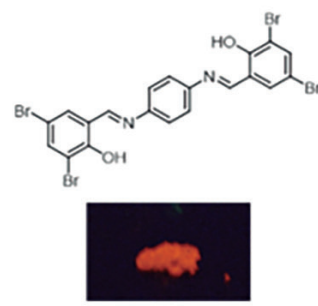

$3 \%$

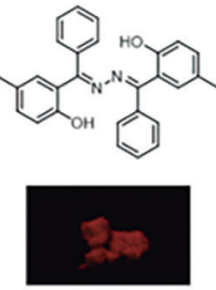

$4 \%$

Figura 11 - Estrutura dos fluoróforos, sólidos iluminados a 365 nm e rendimentos quânticos no estado sólido.
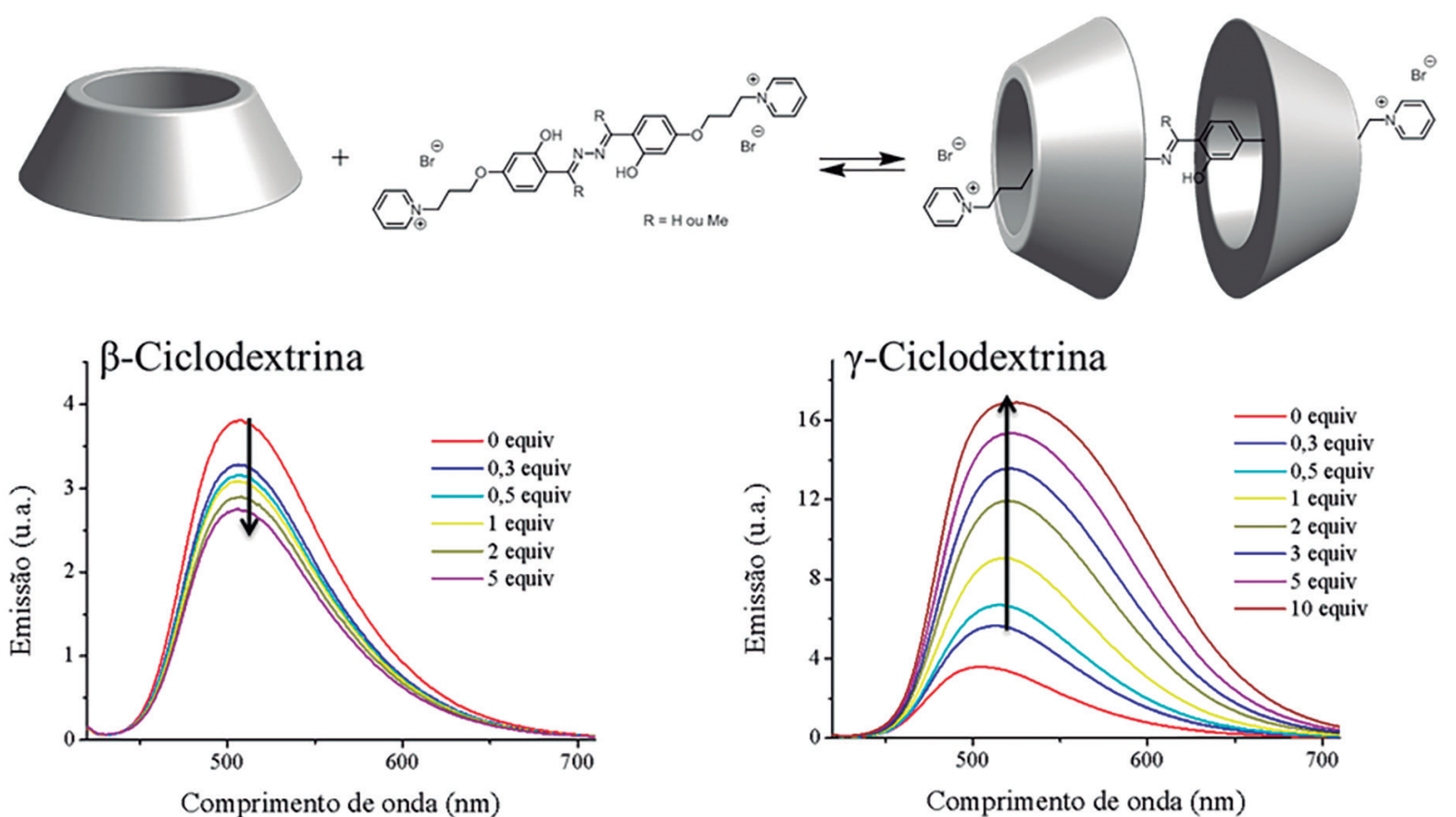

Comprimento de onda $(\mathrm{nm})$

Figura 12 - Formação de complexos de inclusão de fluoróforos em ciclodextrinas. Espetros de emissão de uma solução de fluoróforo com adição de uma solução de ciclodextrina. 
fluoróforo inserido em duas ciclodextrinas. Assim, o aumento da intensidade de emissão do fluoróforo é consequência da sua inserção dentro da cavidade, o que restringe as suas vibrações num processo semelhante ao da cristalização. Este aumento da emissão pode ser usado para detetar a presença de gama-ciclodextrina em soluções aquosas.

\section{Conclusão e perspetivas}

Os fluoróforos orgânicos foram muito usados em soluções diluídas, porque se pensava que a formação de agregados implicava uma perda de eficiência na emissão ou que não era possível controlar o efeito da agregação nas suas propriedades fotofísicas. Mas isso não é verdade para todos os fluoróforos. Pelo contrário, a formação de dímeros $J$, ou a rigidificação da estrutura dos fluoróforos por agregação ou por inclusão em macrociclos pode aumentar a intensidade da emissão. Esse é um método alternativo para produzir sólidos orgânicos que emitem numa vasta gama do espetro visível. Este fenómeno pode ser usado para o estudo do meio onde o fluoróforo se encontra ou para a deteção de analitos.

\section{Agradecimentos}

Agradece-se a Universidade de Aveiro e à FCT/MEC o suporte financeiro às unidades de investigação QOPNA (FCT UID/QUI/00062/2013) e CICECO - Aveiro Institute of Materials (POCI-01-0145-FEDER-007679; FCT - UID/CTM/50011/2013), e a bolsa atribuída a S. Guieu (SFRH/BPD/70702/2010). Agradece-se também ao projeto pAGE-Agregação proteica ao longo da vida (CENTRO01-0145-FEDER-000003).

\section{Referências}

[1] B. Valeur, M.N. Berberan-Santos, J. Chem. Educ. 88 (2011) 731-738.

[2] Y. Hong, J.W.Y. Lam, B.Z. Tang, Chem. Soc. Rev. 40 (2011) 5361-5388.

[3] J. Mei, Y. Hong, J.W.Y. Lam, A. Qin, Y. Tang, B.Z. Tang, Adv. Materials 26 (2014) 5429-5479.

[4] J. Mei, N.L.C. Leung, R.T.K. Kwok, J.W.Y. Lam, B.Z. Tang, Chem. Rev. 115 (2015) 11718-11940.

[5] Y. Jin, Y. Xu, Y. Liu, L. Wang, H. Jiang, L. Xianjie, D. Cao, Dyes Pigments 90 (2011) 311-318.

[6] S. Guieu, J. Rocha, A.M.S. Silva, Tetrahedron 69 (2013) 9329-9334.

[7] M. Kasha, H.R. Rawls, M. Ashraf El-Bayoumi, Pure Appl. Chem. 11 (1965) 371-392.

[8] E.E. Jelley, Nature 138 (1936) 1009-1010.

[9] E.E. Jelley, Nature 139 (1937) 631.

[10] F. Würthner, T.E. Kaiser, C.R. Saha-Möller, Angew. Chem. Int. Ed. 50 (2011) 3376-3410.

[11] S. Guieu, J. Pinto, V.L.M. Silva, J. Rocha, A.M.S. Silva, Eur. J. Org. Chem. (2015) 3423-3426.

[12] J. Wu, W. Liu, J. Ge, H. Zhang, P. Wang, Chem. Soc. Rev. 40 (2011) 3483-3495.

[13] Q. Hu, M. Gao, G. Feng, B. Liu, Angew. Chem. Int. Ed. 53 (2014) 14225-14229.

[14] N.L.C. Leung, N. Xie, W. Yuan, Y. Liu, Q. Wu, Q. Peng, Q. Miao, J.W.Y. Lam, B.Z. Tang, Chem. Eur. J. 20 (2014) 15349-15353.

[15] A. Saeed, M. Bolte, M. Arshad, Acta Cryst. E68 (2012) 0255.

\section{Atualidades Científicas}

\section{Síntese total da ceanotina D}

Os alcaloides ciclopeptídeos são uma família de produtos naturais isolados de folhas, de cascas de caules e raízes, e de sementes de uma grande variedade de espécies de plantas. O seu papel nas plantas não foi ainda totalmente elucidado pois os baixos rendimentos obtidos no processo de extração e nas sínteses têm impedido um estudo mais aprofundado das suas propriedades. Portanto, é natural que diferentes abordagens sintéticas tenham sido desenvolvidas desde a sua descoberta. Um dos alcaloides deste tipo que tem sido estudado é a ceanotina D, presente num arbusto nativo da América do Norte, Ceanothus americanus, vulgarmente conhecido, entre outros nomes, como chá de Nova Jérsia. A estrutura deste alcaloide foi proposta com base em espetroscopia de RMN 1H, espetrometria de massa e estudos de degradação. No entanto, a sua síntese total e caracterização completa ainda não tinha sido publicada.

J. Lee e M.M. Joullié, da Universidade da Pensilvânia (EUA), realizaram a primeira síntese total da ceanotina D usando um novo método de macrociclização em oito passos, partindo da N-Boc-D-serina, com um rendimento global de 8,4\%. Segundo os autores, a estratégia de síntese usada pode ser aplicada na obtenção de outros alcaloides ciclopep-

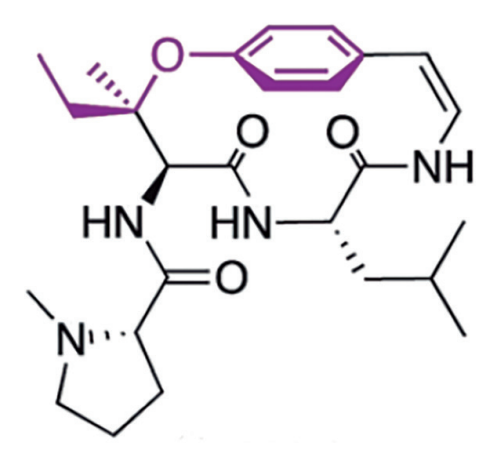
tídeos estruturalmente semelhantes, permitindo novos estudos na área da química e biologia.

\section{Fontes:}

First total synthesis of ceanothine D, http://www.chemistryviews.org/details/news/10841772/First_Total_Synthesis_ of_Ceanothine_D.html (Acedido em 02/02/2018)

J. Lee, M.M Joullié. Total synthesis of the reported structure of ceanothine D via a novel macrocyclization strategy. Chem. Sci. 9 (2018) 2432-2436.

Paulo Mendes (pjgm@uevora.pt) 